\title{
LIBERDADE DE EXPRESSÃO E DIREITO À HONRA: MEDINDO ATITUDES E PREVENDO DECISÕES ${ }^{1}$
}

\section{FREE SPEECH AND PERSONALITY RIGHTS: MEASURING ATTITUDES AND PREDICTING DECISIONS}

\author{
Guilherme da Franca Couto Fernandes de Almeida ${ }^{2}$ \\ Fábio Carvalho Leite ${ }^{3}$ \\ Ivar Allan Rodriguez Hannikainen ${ }^{4}$
}

\begin{abstract}
Resumo: Os conflitos entre liberdade de expressão e direito à honra e à imagem no Brasil são regulados por meio de padrões vagos. Essa vagueza é muitas vezes defendida em nome de posições particularistas. No presente artigo, propomos uma escala que permite medir as atitudes que as pessoas têm a respeito desses conflitos. Ao longo de 4 estudos, desenvolvemos, validamos e aplicamos esse instrumento de pesquisa para testar hipóteses específicas. Nossos resultados mostram que a pontuação de cada respondente na escala exerce influência expressiva sobre as decisões tomadas por juristas e leigos em conflitos entre a liberdade de expressão e o direito à honra e à imagem (estudos 1 e 2). Ademais, as atitudes dos participantes nos estudos a respeito da liberdade de expressão e do direito à honra e à imagem se mantiveram relativamente estáveis ao longo do tempo (estudo 3). Finalmente, a influência exercida pelas posições prévias se mantém mesmo quando controlamos para as diferenças moralmente relevantes entre casos diferentes (estudo 4).
\end{abstract}

Palavras-chave: Liberdade de Expressão. Honra e Imagem. Estudos Empíricos em Direito. Direito e Psicologia.

\begin{abstract}
Conflicts between freedom of speech and personality rights in Brazil are regulated by vague standards - a vagueness that is often cherished by proponents of particularism. In this paper, we introduce a psychometric scale that allows researchers to capture individual differences in attitudes towards these conflicts. Throughout 4 studies, we develop, validate and apply this research instrument to test specific hypotheses. Our results show that both lay people and lawyers' scores influence their decisions in cases concerning conflicts between free speech and personality rights (studies 1 and 2). Moreover, participants' attitudes towards free speech and personality rights showed test-retest reliability (study 3). Finally, participants' previously held attitudes towards those legal standards exert an influence over their judgments even when we account for morally relevant differences between cases (study 4).
\end{abstract}

Keywords: Free Speech. Personality Rights. Empirical Legal Studies. Law and Psychology.

Recebido em 7 de abril de 2019 Avaliado em 25 de outubro de 2019 (AVALIADOR A) Avaliado em 6 de novembro de 2019 (AVALIADOR B) Avaliado em 25 de novembro de 2019 (AVALIADOR C)

Aceito em 9 de dezembro de 2019

\footnotetext{
O presente trabalho foi realizado com apoio do CNPq - Conselho Nacional de Desenvolvimento Científico e Tecnológico - Brasil.

2 Mestre em Direito Constitucional e Teoria do Estado pela Pontifícia Universidade Católica do Rio de Janeiro; Coordenador do Projeto Supremo em Números da Fundação Getúlio Vargas do Rio de Janeiro; Rua Praia de Botafogo, 190, 13ªndar, Botafogo, 22250-900, Rio de Janeiro, Rio de Janeiro, Brasil; https://orcid.org/0000-0002-9134-9843; guilherme.almeida@fgv.br

3 Doutor em Direito Público pela Universidade do Estado do Rio de Janeiro; Professor de Direito Constitucional (graduação e pós-graduação stricto sensu) na Pontifícia Universidade Católica do Rio de Janeiro; https://orcid.org/0000-0003-14533441; fabiojur@puc-rio.br

4 Doutor em Filosofia pela Universidade de Sheffield, Inglaterra; Professor no Programa de Pós-graduação em Direito da Pontifícia Universidade Católica do Rio de Janeiro; https://orcid.org/0000-0003-0623-357X; ivar.hannikainen@gmail.com
} 


\section{Introdução}

A liberdade de expressão, no Brasil, é regulada através de padrões com fronteiras vagas. Se a Constituição estabelece que "é livre a expressão da atividade intelectual, artística, científica e de comunicação" (art. 5a , IX) (BRASIL, 1988), por outro também assegura como "invioláveis a intimidade, a vida privada, a honra e a imagem das pessoas, assegurado o direito a indenização pelo dano material ou moral decorrente de sua violação" (art. 5 X) (BRASIL, 1988). A Constituição, todavia, não define onde exatamente termina a liberdade de expressão e começa o direito à honra e à imagem.

À primeira vista, a questão parece ser simplesmente a respeito da vagueza. Afinal, o direito usa expressões que incorporam conceitos com limites vagos à sua linguagem o tempo todo. Um bom exemplo está na regra que regulamenta o consumo de drogas ilícitas. Como diferenciar um usuário de drogas de um traficante? $O \$ 2^{\circ}$ do art. 28 da Lei n. 11.343/2006 aponta para a quantidade de drogas encontrada com a pessoa como critério (BRASIL, 2006). ${ }^{5}$ Trata-se de um critério vago: ${ }^{6}$ nunca parece justo dizer que um grama de maconha é suficiente para diferenciar um traficante de um usuário. Sua vagueza, porém, não impede que a lei de drogas sirva como um guia para conduta. Sabemos que um único cigarro de maconha claramente não configura tráfico de drogas e que um caminhão contendo toneladas da droga estabelece de maneira inequívoca a incidência da regra mais rígida.

No caso dos conflitos entre liberdade de expressão e direito à honra e à imagem, a situação é diferente. Não possuímos sequer exemplos centrais capazes de distinguir zonas de certeza quanto à incidência de cada um dos direitos. $O$ que torna o cenário brasileiro um caso um tanto peculiar quanto à liberdade de expressão não é a ausência de regras específicas e claras, ${ }^{7}$ mas uma resistência ativa à adoção de regras, lastreada em uma crença de que os conflitos entre liberdade de expressão e direito à honra e à imagem só podem ser decididos de forma particularista. Tal abordagem, adotada por um influente conjunto de juristas brasileiros (que ora se identificam como neoconstitucionalistas, ora como proponentes do direito civil-constitucional), defende que apenas a avaliação das peculiaridades de cada caso é capaz de gerar respostas adequadas aos valores constitucionalmente protegidos e aos direitos humanos.

Pensamento muito semelhante pode ser identificado em Portugal, que resiste a standards normativos construídos pelo Tribunal Europeu de Direitos Humanos (TEDH), preferindo insistir numa abordagem particularista e casuística para lidar com os conflitos entre liberdade de expressão e direito à

\footnotetext{
5 O referido inciso não estabelece a quantidade como o único critério, o que complicaria a análise. Como ilustração do ponto filosófico mais geral que pretendemos avançar, considerar esse universo normativo simplificado é argumentativamente útil, ainda que não seja informativo a respeito da lei de drogas.

6 E extensionalmente vago, se formos mais precisos. Para uma visão geral em português a respeito da vagueza no direito, ver Almeida (2017).

7 Quando falamos de regras, estamos nos referindo a prescrições determinadas, que descrevem de forma clara suas hipóteses de aplicação. No vocabulário introduzido por Schauer (1997), usamos o termo "regra" para nos referir às prescrições específicas, em oposição a prescrições vagas, que não são capazes de determinar sua aplicação como uma função da linguagem utilizada (nesse sentido, "vago", aqui, é utilizado de maneira menos técnica, vide Almeida (2017)). No jargão jurídico brasileiro, é comum usar "regra" como sinônimo de regra jurídica legislativamente criada (lei). Não é esse o sentido que utilizamos. No nosso sentido, regras podem estar contidas em leis, súmulas, enunciados jurisprudenciais ou até mesmo na doutrina. O que importa não é a fonte da regra, mas sim o seu grau de especificidade linguística.
} 
honra e à imagem. ${ }^{8}$ Coincidência ou não, Portugal foi condenado pelo TEDH absolutamente todas as vezes em que foi julgado pelo tribunal por decisões judiciais internas contrárias à liberdade de expressão ou de imprensa (privilegiando direitos da personalidade). ${ }^{9}$ A semelhança entre a jurisprudência brasileira e a portuguesa, e seus problemas, é tão impressionante que um dos inúmeros casos em que Portugal foi condenado pelo TEDH tratava de um político que havia se referido a outro político como "mentiroso comprovado e assumido." (Caso Almeida Azevedo c. Portugal) (CENTRO DE ESTUDOS JUDICIÁRIOS, 2013, p. 247). No Brasil, o Superior Tribunal de Justiça (reformando o entendimento das instâncias anteriores) condenou um deputado por ter afirmado em programa de rádio que outro deputado "tem uma facilidade incrível de mentir." (Recurso Especial n. 801.249/SC) (BRASIL, 2007). Além dos fatos, dos resultados e das fundamentações nos dois casos, outra semelhança (provável) é que dificilmente se poderia assumir que estas decisões, tanto no Brasil como em Portugal, resolveram a questão, firmando um estranho entendimento de que nem mesmo um político poderia chamar outro político de mentiroso.

Para os autores dessas escolas (neoconstitucionalismo, direito civil-constitucional), a resolução de conflitos entre direitos fundamentais a partir da adoção de leis e regras, aplicadas a partir de métodos subsuntivos, representaria um modelo arcaico e ultrapassado de interpretação e aplicação do direito (SILVA, 2005, p. 116). Essa estratégia, calcada na supressão de uma série de considerações importantes, levaria, inevitavelmente, a casos onde os propósitos constitucionais são flagrantemente frustrados. Por conseguinte, seria preferível adotar textos normativos vagos, que permitem que o juiz adeque a solução recomendada às peculiaridades do caso concreto. ${ }^{10}$ Barroso

\footnotetext{
8 Este trecho de um acórdão do Tribunal da Relação de Lisboa é bem ilustrativo: "É verdade que existem várias decisões do TEDH que permitem uma crítica e ofensa quase ilimitada do direito à honra, estribando-se no direito à liberdade de expressão." O TEDH considera que "a liberdade de expressão constitui um dos fundamentos essenciais de uma sociedade democrática" a qual é caracterizada ainda pelo "pluralismo, tolerância e espírito de abertura", sendo uma "das condições primordiais do seu progresso e do desenvolvimento de cada um." Esta leitura da CEDH por parte do TEDH conflita, a nosso ver, com o direito interno português e a interpretação que a maioria da doutrina e da jurisprudência fazem da colisão de direitos constitucionais com igual dignidade abstrata. Porém, em nosso entender, tal jurisprudência comunitária não é vinculativa dos tribunais portugueses. (PORTUGAL, 2017).

9 International Press Institute (2015). De acordo com o relatório Criminalização da Difamação em Portugal elaborado pelo International Press Institute (IPI), Portugal sofreu 18 condenações entre janeiro de 2005 e janeiro de 2015, o triplo da média dos 28 Estados-membros. Até 31 de dezembro de 2016, ocorreram mais 5 condenações. E é importante recordar que o TEDH adota a doutrina da "margem de apreciação", que impõe à Corte internacional uma postura mais deferente aos tribunais nacionais, respeitando as decisões por eles proferidas, seja pela diversidade moral ou cultural entre os Estados, seja porque as autoridades nacionais (locais) estariam em melhor posição para decidirem os casos. Isso significa, portanto, que o TEDH não aceitou sequer o argumento de que as ponderações realizadas pelos magistrados portugueses poderiam ser respeitadas a partir da doutrina da margem de apreciação. Em entrevista concedida à imprensa portuguesa em dezembro de 2016, o presidente do Tribunal Europeu, Guido Raimondi, ao tratar das constantes condenações de Portugal, sugeriu: "o mais importante é que os juízes nacionais incluam a Convenção dos Direitos Humanos nas suas decisões, usando os princípios da jurisprudência do TEDH." (HENRIQUES; BARATA; PEDRO, 2016).

10 Existem posições mais sofisticadas na doutrina, que apontam para o método da ponderação ou para o princípio da proporcionalidade como maneiras eficazes - e baseadas em alguma fonte normativa - de resolver conflitos entre direitos fundamentais como o que nos preocupa no presente artigo. Em que pese à importância e à influência desses parâmetros no pensamento jurídico brasileiro (HARTMANN, 2018), há razões para o ceticismo. Alexander e Sherwin, por exemplo, argumentam que raciocínios principiológicos invariavelmente colapsam em raciocínios particularistas (ALEXANDER; SHERWIN, 2008, p. 95-97). Se eles estão certos com relação a isso, os modelos mais sofisticados de tomada de decisão adotados por juristas brasileiros com base na doutrina alemã seriam equivalentes ao tipo de particularismo que pretendemos discutir no artigo. Foge ao nosso escopo analisar esse argumento de maneira mais detida, mas, independentemente disso, a melhor evidência empírica que temos a nosso dispor (HARTMANN, 2018) aponta que juízes brasileiros (pelo menos no TJRJ) não aplicam essas teorias mais sofisticadas, justificando a análise do modelo particularista.
} 
(2004, p. 6-7), um dos principais proponentes desse modo de interpretação constitucional, coloca a questão nos seguintes termos:

Situação diversa se coloca, porém, quando o legislador procura arbitrar diretamente colisões entre direitos. Como se afirmou acima, uma regra que estabeleça uma preferência abstrata de um direito fundamental sobre outro não será válida por desrespeitar o direito preterido de forma permanente e violar a unidade da Constituição. O legislador, portanto, deverá limitar-se a estabelecer parâmetros gerais, diretrizes a serem consideradas pelo intérprete, sem privá-lo, todavia, do sopesamento dos elementos do caso concreto e do juízo de eqüidade que lhe cabe fazer. Mesmo nas hipóteses em que se admita como legítimo que o legislador formule uma solução específica para o conflito potencial de direitos fundamentais, sua validade em tese não afasta a possibilidade de que se venha a reconhecer sua inadequação em concreto. ${ }^{11}$

Uma interpretação caridosa da posição defendida por Barroso pressupõe que as propriedades moralmente relevantes dos casos concretos exercem mais peso sobre a decisão final do que as preferências normativas do julgador. Muito embora diferentes juízes tenham concepções diferentes de qual é a quantidade de drogas que separa usuários de traficantes, temos que pressupor que há certa convergência: assim, por mais que possamos ter dúvidas genuínas sobre se alguém que carrega maconha suficiente para 10 cigarros deve ser tratado como usuário ou traficante, não podemos ter dúvidas sobre os casos nos quais a pessoa porta um único cigarro, nem sobre os casos nos quais ela é encontrada com toneladas de droga. Mesmo o juiz mais pró-legalização será forçado a dizer que o sujeito que carrega toneladas de drogas é traficante e o juiz mais punitivista será obrigado a aceitar que um único cigarro é uma quantia destinada ao uso próprio. Se a maioria dos casos é decidida com base nas convicções pessoais do juiz (e.g., sua simpatia com o movimento pela legalização na maconha) e não com base nas características singulares do caso concreto, o particularismo à moda Barroso perde seu apelo.

Existe, porém, uma lacuna entre a maneira como as coisas são e como elas deveriam ser. Estudos prévios sobre a resolução de conflitos entre liberdade de expressão e os direitos à honra e à imagem pelos tribunais mostram que juristas discordam radicalmente a respeito da solução correta a ser adotada em casos concretos (HARTMANN, 2018; LEITE, 2018; LEITE; FRAJHOF, 2018; LEITE; HANNIKAINEN, 2018; LEITE; HANNIKAINEN; NHUCH, 2016). Em outras palavras, as decisões parecem variar de acordo com as convicções pessoais de cada julgador, mesmo quando os casos são exatamente iguais.

No presente artigo, buscamos explorar essa hipótese por meio de uma escala que mede as atitudes das pessoas com relação à liberdade de expressão e ao direito à honra. Ao longo de 4 estudos, desenvolvemos, validamos e aplicamos esse instrumento de pesquisa para testar hipóteses específicas. Nossos resultados mostram que a pontuação de cada respondente na escala exerce influência expressiva

\footnotetext{
$\overline{11}$ Moraes (2012) seria um exemplo igualmente eloquente da posição que queremos discutir. Em linhas gerais, tomamos como não problemáticas as afirmações de que: 1) existem no universo jurídico brasileiro correntes de pensamento que defendem métodos particularistas de tomada de decisão jurídica (quer chamemos essas correntes de neo-constitucionalistas, direito civil constitucional ou qualquer outro apelido) e 2) essas correntes são majoritárias. No mesmo sentido, Leal (2015).
} 
sobre as decisões tomadas por juristas e leigos em conflitos entre a liberdade de expressão e o direito à honra e à imagem (estudos 1 e 2). Ademais, as posições dos participantes nos estudos a respeito da liberdade de expressão e do direito à honra e à imagem se mantiveram relativamente estáveis ao longo do tempo (estudo 3). Finalmente, a influência exercida pelas posições prévias se mantém mesmo quando controlamos para as diferenças moralmente relevantes entre casos diferentes (estudo 4).

$\mathrm{Na}$ conclusão, discutimos em que medida os resultados alcançados sugerem a necessidade de reavaliação das principais premissas da posição particularista. Será que, à luz dos efeitos práticos da doutrina, ela continua sendo desejável do ponto de vista normativo? Quais alternativas temos a essa posição? Será que elas são capazes de alcançar resultados práticos melhores? Finalmente, discutimos as limitações dos estudos reportados no presente artigo e indicamos as questões que pretendemos perseguir em pesquisas futuras.

\section{Método}

Os participantes dos estudos (à exceção do estudo 3) foram recrutados através de postagens em redes sociais ${ }^{12}$ realizadas pelos autores e membros da PLEB (grupo de Pesquisa sobre Liberdade de Expressão no Brasil, coordenado pelo segundo autor - Fábio Leite - no âmbito do Programa de PósGraduação em Direito da PUC-Rio), assim como posts patrocinados no Facebook, veiculados através da página do grupo de pesquisa. ${ }^{13}$ As respostas foram colhidas através da plataforma Qualtrics. Todas as análises e dados estão disponíveis nos materiais suplementares. ${ }^{14}$

Pesquisas pregressas indicam que o treinamento recebido por juristas exerce influência sobre julgamentos jurídicos (KAHAN et al., 2016). Para testar se esse é o caso com relação à liberdade de expressão, reportamos análises separadas excluindo participantes que reportaram formação/ atuação profissional extra-jurídica em todas as ocasiões nas quais a distinção era aplicável.

\section{Estudo 1 \\ Procedimento}

No primeiro estudo realizado, os participantes recebiam uma de duas vinhetas descrevendo o caso de Toninho Malícia, um ex-jogador de futebol que buscava uma liminar na justiça para impedir

12 Era feito um post com uma chamada a participar do experimento e um link para o formulário on-line.

13 Não ignoramos que a nossa amostra pode representar uma população específica, com diferenças significativas com relação à população brasileira como um todo. Dessa forma, as conclusões que delineamos devem ser interpretadas com certa cautela até que os resultados sejam replicados em outros locais do Brasil, com prevalência de diferentes grupos demográficos e métodos de amostragem mais robustos.

14 Acessíveis em: https://osf.io/qtkf3. A disponibilização do código das análises, assim como dos dados anonimizados, é importante do ponto de vista normativo (MUNAFÒ et al., 2017). No presente caso, ela é especialmente importante, posto que, para facilitar a comunicação dos resultados para o público jurídico, reportamos apenas as métricas mais importantes e, ainda assim, em notas de rodapé. Confiamos que o leitor metodologicametne sofisticado irá recorrer aos materiais suplementares para avaliar o mérito acadêmico do presente artigo. 
a veiculação de um programa de televisão que retratava os excessos que cometera na juventude. ${ }^{15}$ Após a leitura, os participantes deveriam responder à seguinte pergunta: "Como juiz, você decidiria o caso em favor de quem?"

As respostas que decidiram o caso a favor de Toninho, determinando a proibição de veiculação do programa televisivo, foram codificadas como contrárias à liberdade de expressão, enquanto as respostas que negaram o pedido foram codificadas como favoráveis. A única diferença entre as duas versões da vinheta era a fundamentação: na condição 1 Toninho fundamentava seu pedido no direito à honra e à imagem, enquanto na condição 2 a razão de pedir era o direito ao esquecimento. Na sequência, os participantes eram instruídos a responder (em uma escala de seis pontos) se concordavam ou discordavam com os cinco itens da escala de liberdade de expressão/ direito à honra ("escala da PLEB"):

Responda se concorda/discorda (fortemente/moderadamente/levemente) com as frases abaixo:

1) Defender a honra dos cidadãos é um dos mais importantes deveres de um Estado de direito.

2) A liberdade de expressão é um elemento fundamental para a democracia.

3) A liberdade de expressão acaba onde a dignidade de alguém é ferida.

4) A liberdade de expressão deve ser protegida mesmo que o(a) outro(a) se sinta ofendido(a).

5) A liberdade de expressão tem uma posição preferencial face ao direito à honra.

Ao fim do questionário, foram colhidas informações demográficas a respeito dos participantes.

\section{Validação da escala}

A escala da PLEB se mostrou consistente, com correlação entre os itens da escala, o que indica que todos eles medem a mesma coisa; no caso, as atitudes frente à liberdade de expressão e o direito à honra e à imagem. ${ }^{16} \mathrm{O}$ único item cuja exclusão aumentaria marginalmente a consistência (item 2: "A liberdade de expressão é um elemento fundamental para a democracia") foi mantido por capturar um aspecto um pouco diferente da atitude dos respondentes com relação à liberdade de expressão, no que é acompanhado pelo item 1 da escala.

\footnotetext{
15 Uma versão completa da vinheta pode ser encontrada nos materiais suplementares ao presente artigo.

$16 \mathrm{O} \alpha$ de Cronbach, principal métrica de consistência interna para instrumentos psicológicos, se mostrou alto (0,77). Da mesma forma, uma análise fatorial exploratória (operacionalizada através do método "fa", do pacote de R "psych" (REVELLE, 2017), revelou a significância da relação dos itens da escala entre si, que foram reduzidos a um único fator - conclusão a que chegamos através da análise de um "scree plot".
} 


\section{Resultados}

Completaram o experimento 194 participantes (média de idade: 30,83; 93 mulheres). ${ }^{17}$ O caso se mostrou razoavelmente controverso, ainda que a maioria dos respondentes (65\%) tenha decidido pela prevalência da liberdade de expressão. Com a exclusão de não juristas, contamos com um universo final de 171 participantes (média de idade: 31,3; 77 mulheres).

A pontuação na escala de liberdade de expressão se correlacionou positivamente com julgamentos pró-liberdade de expressão. ${ }^{18}$ Para explorar de maneira mais rigorosa os elementos que influenciaram a tomada de decisão, criamos um modelo estatístico ${ }^{19}$ que buscava os fatores que melhor explicavam o resultado do julgamento ( 0 = contra; 1 = a favor da liberdade de expressão). Esse modelo levava em conta o gênero ( 1 = homens; 2 = mulheres) e a idade do participante, assim como a condição ( 0 = honra e imagem; 1 = direito ao esquecimento) da vinheta que foi apresentada a ele e, finalmente, sua pontuação ${ }^{20}$ na escala da PLEB.

Tabela 1 - Modelo de regressão logística com todos participantes

\begin{tabular}{lc}
\hline & Variável independente \\
\cline { 2 - 2 } Condição & Resposta $(0=$ contra, 1 a favor da liberdade de expressão $)$ \\
Gênero & $2.238^{* *}$ \\
& $(0.863)$ \\
Idade & 0.779 \\
& $(0.326)$ \\
Pontuação na escala & 1.030 \\
& $(0.022)$ \\
Constant & $1.378^{* * *}$ \\
& $(0.071)$ \\
Observations & $0.002^{* * *}$ \\
Log Likelihood & $(0.003)$ \\
Akaike Inf. Crit. & 194 \\
\hline
\end{tabular}

Fonte: os autores.

Nota: ${ }^{*} \mathrm{p}<0.1 ; * \mathrm{p}<0.05 ; * * \mathrm{p}<0.01$

17 As análises da hipótese principal do estudo foram reportadas em Leite e Frajhof (2018). No presente artigo, estamos interessados em outro conjunto de questões que foram exploradas na mesma ocasião. Muito embora tenhamos incluído os efeitos principais de condição (direito ao esquecimento x direito à honra/imagem), estes não dizem respeito ao nosso argumento. Uma terceira condição experimental também foi passada ao mesmo conjunto de participantes, com uma versão menos empática e bem mais curta das vinhetas. Não consideramos essas (88) respostas em nossa análise de nenhum dos dois experimentos.

18 Correlação ponto-bisserial $=0,55, \mathrm{p}<0,001$.

19 De regressão logística linear.

20 Para testar a validade da agregação dos itens da escala através da soma, comparamos a estatística de adequação de modelos de regressão logística que tomavam como variável dependente o julgamento e como variáveis independentes: 1) os itens individuais da escala e 2) os itens agregados através da soma dos valores, após ser feita a codificação reversa dos itens negativos (1 e 3). A comparação mostrou baixa diferença entre a qualidade relativa dos modelos (AICmodelo $1=187,48$; AICmodelo 2 = 198,93). Desta forma, para simplificar as regressões que se seguem e evitar problemas de multicolinearidade, usamos o método agregado, que chamaremos de pontuação, para realizar as análises que incorporam a escala 
Esse modelo, ${ }^{21}$ sumarizado na Tabela 1, mostrou a significância estatística da pontuação na escala como preditor da resposta. Cada ponto a mais na escala ( 5 = totalmente contrário à liberdade de expressão; 30 = totalmente favorável à liberdade de expressão) reduzia significativamente a probabilidade de que o respondente decidiria a favor de Toninho. Quando levamos em conta apenas os respondentes com treinamento jurídico, os resultados se mantiveram inalterados (ver Tabela 2). ${ }^{22}$

Tabela 2 - Modelo de regressão logística com juristas

\begin{tabular}{|c|c|}
\hline & Variável independente \\
\hline & Resposta $(0=$ contra, $1=$ a favor da liberdade de expressão) \\
\hline Condição & $\begin{array}{c}1.745 \\
(0.609)\end{array}$ \\
\hline Gênero & $\begin{array}{c}0.423^{* *} \\
(0.153)\end{array}$ \\
\hline Idade & $\begin{array}{c}1.005 \\
(0.017)\end{array}$ \\
\hline Pontuação na escala & $\begin{array}{c}1.228 * * * \\
(0.081)\end{array}$ \\
\hline Constant & $\begin{array}{c}0.063^{* * *} \\
(0.105) \\
\end{array}$ \\
\hline Observations & 171 \\
\hline Log Likelihood & -99.964 \\
\hline Akaike Inf. Crit. & 209.927 \\
\hline
\end{tabular}

Fonte: os autores.

Nota: ${ }^{*} \mathrm{p}<0.1 ;{ }^{*} \mathrm{p}<0.05 ;{ }^{* *} \mathrm{p}<0.01$.

O gráfico abaixo mostra o julgamento esperado ${ }^{23}$ de juristas e leigos a respeito do caso de Toninho como uma função da pontuação relativa do respondente na escala de liberdade de expressão (-2 = a parcela da amostra mais favorável ao direito à honra e à imagem, 0 = pontuação na média; $+2=$ parcela mais favorável à liberdade de expressão). ${ }^{24}$

21 Assim, se um participante com pontuação mínima na escala tem $10 \%$ de chances de dizer que a liberdade de expressão merece prevalecer (odds de 1:9, ou 0.11), um participante com um ponto a mais e equivalente em todas as outras variáveis tem $13,3 \%$ (odds/(1+odds), ou $0.153 /(1+0.153)$ ) de chances de considerar que o caso viola a liberdade de expressão (odds de $0.11 * 1.378$, ou 0.153 ). Da mesma forma, outro participante com ainda mais um ponto na escala, quando comparado ao segundo participante, apresentará novo aumento de $37,8 \%$ no odds (odds de $0.153 * 1.378$, ou 0.211 ), passando a ter $17,4 \%$ (odds/(1+odds), ou 0.211/(1+0.211)) de chances de julgar o caso como violando a liberdade de expressão. Abaixo de cada valor de odds ratio, entre parênteses, reportamos o erro padrão do odds ratio.

22 Quando analisamos juristas, percebemos um efeito principal de gênero ( $p<0.001$ ), que indicava que mulheres tendiam a julgar a questão a favor de Toninho. Investigando o resultado mais a fundo, notamos que, na condição 1, mulheres eram 5 vezes mais propensas a decidir a favor de Toninho. Essa preferência, porém, era invertida na interação entre grupo e gênero, indicando que, na condição 2 (direito ao esquecimento) mulheres tendiam a decidir contra Toninho, negando seu pedido $22,5 \%$ mais vezes que homens $(p<0.05)$.

23 Trata-se do resultado previsto por uma regressão linear generalizada que controlava para os efeitos randômicos de idade e gênero sobre o julgamento.

24 Os dados foram normalizados usando a função "scale", nativa da linguagem de programação R. O procedimento subtrai a média geral da pontuação do valor obtido por cada indivíduo e, posteriormente, subtrai o desvio padrão daquele valor. Em todos os experimentos, conforme pode ser verificado nos materiais suplementares, a distribuição da pontuação dos participantes se assemelhava à distribuição normal, justificando o uso dessa normalização. 
Gráfico 1 - Julgamento esperado como função da pontuação

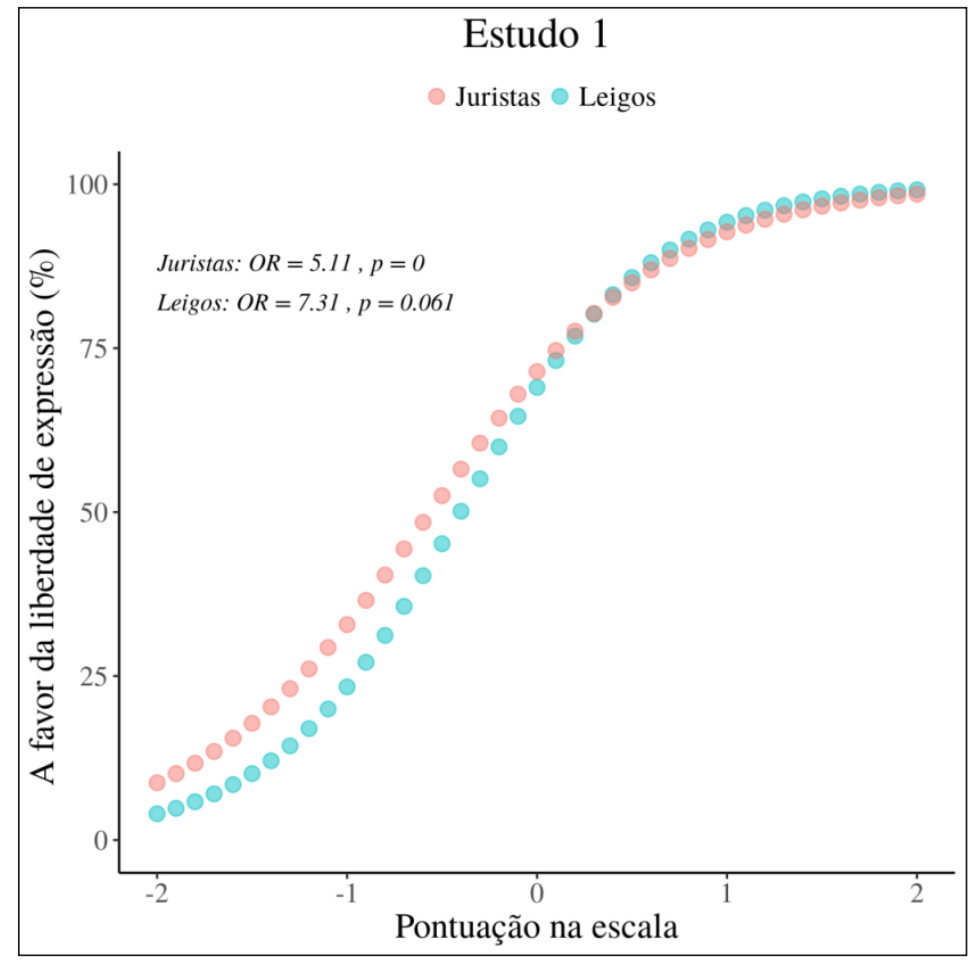

Fonte: os autores.

Para confirmar a relação entre a pontuação na escala e as respostas dadas, utilizamos diversos métodos preditivos que foram alimentados com uma amostra aleatória ${ }^{25}$ contendo $60 \%$ das respostas colhidas (conjunto de dados que, no jargão, é conhecido como de treinamento) e aplicados para prever os $40 \%$ restantes (conjunto de testes). A única variável independente utilizada nos modelos foi a pontuação de cada indivíduo na escala de liberdade de expressão. Os resultados estão sumarizados na tabela abaixo para os recortes com e sem juristas. ${ }^{26}$ Em todas as análises, obtivemos percentuais de acerto acima dos $60 \%$, indicando que a pontuação na escala não funciona somente como um bom fator explicativo das decisões, mas também como subsídio preditivo, ${ }^{27}$ como ilustramos na Tabela 3:

\footnotetext{
25 A amostra em questão era estratificada, o que significa dizer que ela era composta por metade dos casos nos quais os respondentes julgaram a favor de Toninho e metade dos casos nos quais os respondentes julgaram contra Toninho, de maneira que a distribuição final dos resultados na amostra se adequasse da melhor forma possível à distribuição dos resultados no universo dos dados.

26 Os valores reportados referem-se à média após 40 rodadas de treinamento e teste. Os valores entre parênteses ao lado do percentual de acertos indicam os valores mínimo e máximo obtidos nas 40 rodadas e refletem, aproximadamente, o intervalo de confiança de $95 \%$.

27 A literatura sobre aprendizado de máquina é muitas vezes cética a respeito do que se pode inferir a partir do percentual de acerto, razão pela qual adicionamos o kappa à tabela.
} 
Tabela 3 - Contribuição da pontuação na escala por método preditivo e recorte amostral

\begin{tabular}{lrrrrr}
\hline Modelo & \% de acerto & Sensitividade & Especificidade & Kappa & Recorte \\
\hline randomForest (LIAW; WIENER, 2002) & $63,26(47,82-69,56)$ & 85,11 & 22,23 & 0,62 & Juristas \\
\hline randomForest (LIAW; WIENER, 2002) & $76(70,13-81,81)$ & 85,95 & 57,59 & 0,75 & Todos \\
\hline Naïve Bayes & $66,81(63,77-71,0)$ & 94,05 & 15,73 & 0,65 & Juristas \\
\hline Naïve Bayes & $75,65(59,74-81,81)$ & 87,95 & 52,87 & 0,75 & Todos \\
Regressão logística & $66,78(63,77-71,01)$ & 94,6 & 14,58 & 0,65 & Juristas \\
\hline Regressão logística & $74,97(59,74-81,81)$ & 86,25 & 54,01 & 0,74 & Todos \\
\hline
\end{tabular}

\section{Discussão}

As preferências individuais do julgador influenciam significativamente seu julgamento. O estudo 1 mostra esse efeito no caso da liberdade de expressão: mesmo quando controlamos para os efeitos causados por variações de idade, gênero, instrução e condição experimental, subsiste uma influência expressiva das preferências individuais de cada participante sobre seu julgamento.

O que os resultados nos dizem a respeito da tomada de decisão particularista em casos de vagueza? Como estamos falando de variações sobre uma única vinheta, as diferenças em julgamento não podem ser explicadas por diferenças nas peculiaridades do caso concreto: todos os participantes receberam o mesmo caso. Os demais efeitos encontrados também não podem ser invocados para justificar a variação: afinal, o gênero do julgador não parece ser um fator moralmente relevante para a justificação jurídica. ${ }^{28}$ De toda forma, mesmo que algum desses fatores fosse moralmente relevante e, portanto, de influência esperada sob um modelo decisório particularista, não poderíamos ignorar o fato de que um dos melhores - senão o melhor - preditores do comportamento judicial parece ser a pontuação do respondente na escala de liberdade de expressão.

Ademais, os efeitos afetam indiscriminadamente juristas e não-juristas, como mostram as análises em separado. O treinamento jurídico não parece, portanto - de maneira oposta ao reportado em KAHAN et al. (2016) -, eliminar a influência indevida das crenças morais dos julgadores sobre os seus julgamentos. Uma diferença saliente entre os casos narrados por KAHAN et al. (2016) e o utilizado no estudo 1 é que os casos explorados pelo artigo de Kahan e colegas envolviam a aplicação de regras claras, o que nos dá razões redobradas para desconfiar do particularismo jurídico.

Essas conclusões, porém, podem parecer apressadas: vimos apenas um caso e uma dose saudável de ceticismo recomenda que circunscrevamos nossas conclusões a ele. Um defensor do neoconstitucionalismo poderia dizer que essa influência ocorre nesse caso justamente por causa

\footnotetext{
28 O melhor candidato a explicação concorrente e juridicamente válida é o efeito exercido pela condição experimental, onde manipulávamos se o pedido de Toninho tinha sido fundamentado pelo direito à honra e à imagem ou pelo direito ao esquecimento (LEITE; FRAJHOF, 2018). Mesmo esse argumento, porém, é duvidoso. De toda forma, os modelos reportados controlam para os efeitos principais de condição experimental, de maneira que a objeção não poderia afastar totalmente a linha de raciocínio que perseguimos no corpo do texto.
} 
de suas características peculiares. Ele poderia dizer que o caso de Toninho é um caso difícil e que casos difíceis realmente são decididos por detalhes. Talvez, casos mais (ou menos) graves ou que envolvessem considerações distintas (independentes de gênero, por exemplo) fossem decididos irrespectivamente das preferências particulares dos respondentes.

\section{Estudo 2}

\section{Procedimento}

Muitas vezes, estudos realizados com métodos similares aos que empregamos no estudo 1 revelam resultados positivos por fruto do acaso. ${ }^{29}$ É possível que os participantes específicos que responderam às nossas vinhetas naquela ocasião tenham, por coincidência, apresentado uma correlação entre as variáveis de interesse. Uma estratégia comumente empregada para reduzir a probabilidade de que esses falsos positivos aconteçam é testar as mesmas hipóteses novamente, através de estratégias ligeiramente diferentes. Com esse intuito e para explorar uma variedade maior de casos, distribuímos um segundo questionário. Nesse estudo, apresentamos a cada participante uma de 3 vinhetas que criamos a partir de casos reais sobre conflitos entre a liberdade de expressão e a honra de políticos. A título de exemplo, a vinheta 1 contava o seguinte caso: ${ }^{30}$

Adele Santos, ex-prefeita da cidade X, no sul fluminense, ajuizou ação cível contra o conhecido jornal Planeta Diário em razão de uma reportagem onde o matutino a comparava a um "Odorico Paraguaçu de saias". Odorico Paraguaçu - um famoso personagem interpretado por Paulo Gracindo, na novela 'O Bem Amado', da Rede Globo - era considerado um prefeito corrupto e, segundo Adele, ao compará-la com tal personagem, o jornal causou danos morais por injúrias, difamações e calúnias, devendo ser condenado a pagar indenização à ex-prefeita.

Em sua defesa, o jornal alegou que apenas deu publicidade a fatos ocorridos no cenário político da cidade, comparando-os à telenovela 'O Bem Amado', como se os fatos notórios protagonizados pela autora fossem cenas de um folhetim. Ressaltou também que todas as cenas descritas na matéria estão retratadas em procedimentos investigatórios instaurados pelo MP, sendo, portanto, informações oficiais e de interesse público.

Após ler cada vinheta, o participante deveria decidir o caso, julgando-o procedente ou improcedente. Caso julgassem o pedido procedente, os participantes deveriam preencher o valor em

\footnotetext{
29 Recentemente, essa taxa de falsos positivos gerou um debate amplo nos campos da psicologia social. Ver Open Science Collaboration (2015).

30 Assim como no Estudo 1, todas as vinhetas estão disponíveis nos materiais suplementares.
} 
que arbitrariam a condenação. ${ }^{31}$ Finalmente, eram apresentados os itens da escala de liberdade de expressão e perguntas sobre informações demográficas.

Essas vinhetas, construídas com certa diversidade a partir de casos reais, foram incluídas para que os participantes pudessem observar situações com diferentes níveis de gravidade, diferentes fundamentações e diferentes personagens. Testar nossas hipóteses nesse novo conjunto de casos serve, portanto, não só para replicar os resultados originais, como para enfrentar algumas das objeções levantadas na discussão do Estudo 1.

\section{Resultados}

Completaram o questionário 178 participantes (média de idade $=32,65,98$ mulheres). 64 (36 mulheres) viram a vinheta 1, 57 (33 mulheres) viram a vinheta 2 e 57 (29 mulheres) viram a vinheta 3. Entre os grupos, houve variação considerável na taxa de concessão: 23,44\% dos respondentes julgaram a ação descrita na primeira vinheta procedente, contra 49,12\% na segunda vinheta e $28,1 \%$ na terceira. Utilizamos o mesmo critério descrito no Estudo 1 para distinguir entre juristas e não juristas, o que nos deixou com um universo final de 140 (média de idade = 31,44, 76 mulheres) juristas.

Replicamos todas as conclusões do Estudo 1. Mesmo quando controlamos para a variação entre as diferentes vinhetas, além de variáveis demográficas, percebemos uma influência estatisticamente significativa da pontuação na escala de liberdade de expressão sobre os julgamentos de juristas. As análises envolvendo apenas leigos foram pouco conclusivas, haja vista a presença de apenas 38 participantes nesta condição. Os resultados envolvendo métodos preditivos também se repetiram, mostrando ser possível prever os julgamentos individuais a partir da pontuação na escala com resultados acima dos esperados com palpites aleatórios. ${ }^{32}$ Abaixo, representamos graficamente a probabilidade esperada de concordância com o resultado, como uma função da pontuação normalizada na escala da PLEB e controlando-se os efeitos de idade, gênero e caso:

\footnotetext{
31 Assim como o Estudo 1, o Estudo 2 teve a fase de coleta de dados compartilhada com outros estudos que introduziam manipulações experimentais. Analisamos aqui somente uma das duas condições experimentais mais amplas da coleta de dados. Na outra condição os participantes, antes de serem apresentados às vinhetas, liam uma breve descrição de outras ações envolvendo conflitos entre a liberdade de expressão e a honra de políticos. Os resultados dessa análise não alcançaram significância estatística e tratavam de hipóteses diversas daquelas que nos preocupam no presente artigo. Nesta condição, não foi apresentada a escala de liberdade de expressão, como medida para maximizar o número de respondentes que completam o questionário.

32 Todos os resultados estão disponíveis nos materiais suplementares.
} 
Gráfico 2 - Julgamento previsto como função da pontuação na escala no estudo 2

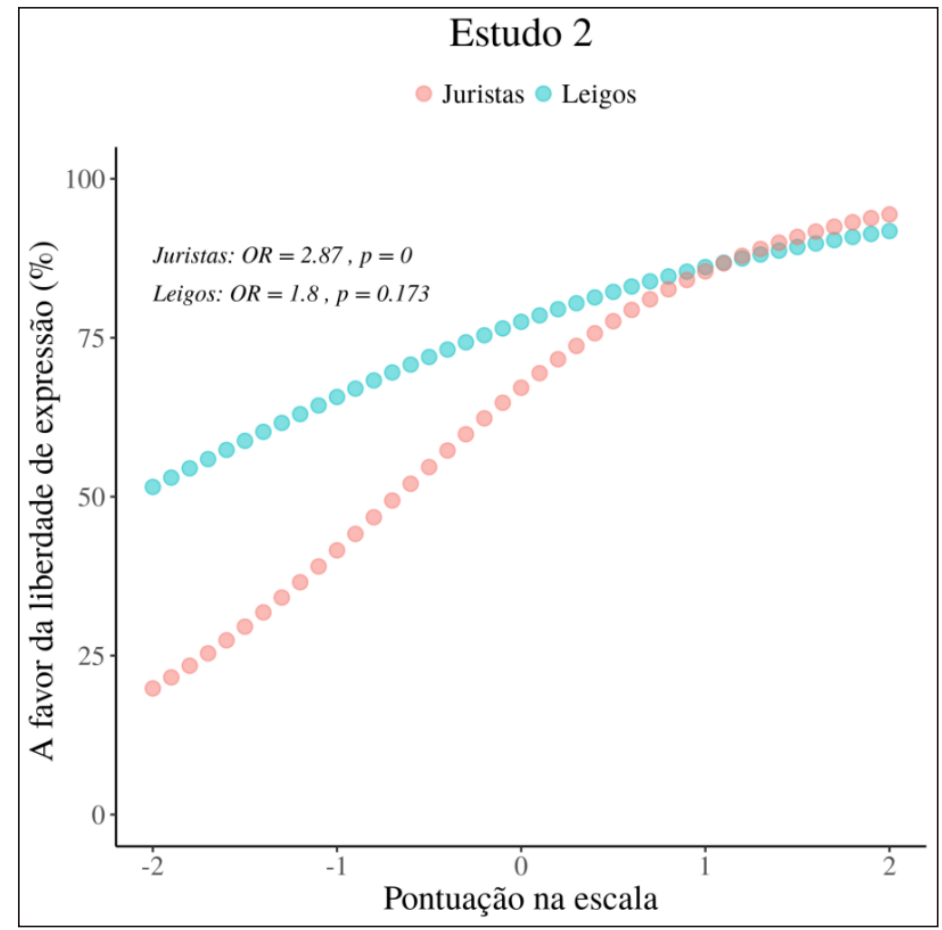

Fonte: os autores.

\section{Discussão}

fato de que os efeitos observados no Estudo 1 se mantêm mesmo com uma variedade maior de casos aumenta nosso grau de confiança nas hipóteses iniciais. Os resultados do segundo experimento indicam que as preferências dos respondentes quanto à liberdade de expressão influenciam os julgamentos realizados mesmo na presença de variações importante entre os casos. Por outro lado, o fato de que a proporção de respostas contrárias à liberdade de expressão foi significativamente menor no caso da segunda vinheta aponta para a existência de alguma sensibilidade às peculiaridades do caso concreto.

Pode ser, porém, que as pessoas não tenham posições estáveis a respeito da liberdade de expressão. Ao invés de medirem posições morais prévias, as respostas dadas aos nossos 2 primeiros estudos podem ser fruto de variações de humor e opinião que estão à mercê de fenômenos psicológicos mais locais. É possível, por exemplo, que a própria vinheta experimental seja capaz de influenciar as posições abstratas dos respondentes a respeito do conflito entre a liberdade de expressão e os direitos à honra e à imagem. 


\section{Estudo 3 \\ Procedimento}

Para testarmos se os resultados se manteriam estáveis ao longo do tempo, aplicamos questionários para os alunos da disciplina ministrada pelo segundo autor (Fábio Leite) na PUC-Rio em dois momentos distintos. No primeiro momento, os participantes respondiam apenas aos itens da escala de liberdade de expressão/direito à honra e perguntas demográficas. Nesta ocasião, lhes foi informado um número que deveria ser anotado de maneira a permitir o reteste. Todos os participantes concordaram com um termo de consentimento e a participação foi totalmente voluntária e anônima. Duas semanas depois, os alunos que retiveram a anotação referente ao seu número responderam a um novo questionário. Nesta ocasião, a primeira folha do questionário continha, novamente, o caso do jogador Toninho Malícia, enquanto na segunda folha os participantes deveriam responder novamente aos itens da escala e a perguntas demográficas. Ambas aplicações ocorreram antes de se iniciarem quaisquer debates em sala de aula a respeito de liberdade de expressão. Dessa forma, embora o estudo conte apenas com a participação de estudantes de direito, tratam-se de estudantes que ainda não tinham tido contato com as discussões acadêmicas que permeiam a liberdade de expressão no Brasil. Isso ajuda a minimizar (embora não seja medida capaz de eliminar) o risco de que eles tenham sido influenciados pela posição esposada pelo professor.

\section{Resultados}

23 (11 mulheres, média de idade $=21,1$ anos) estudantes completaram ambas fases do estudo e foram considerados em nossa análise.

A tabela abaixo mostra as correlações ${ }^{33}$ entre os itens da escala na primeira e na segunda rodada. À exceção do item 2 da escala, que se correlacionou apenas de maneira fraca $(r=0,32)$ às respostas, todos os itens apresentam alta correlação entre os dois momentos:

Tabela 4 - Correlação entre os itens da escala nas duas fases do estudo 3

\begin{tabular}{crrrrr}
\hline & 1 & 2 & 3 & 4 & 5 \\
\hline 1 & 0.77 & & & & \\
2 & 0.07 & $\mathbf{0 . 3 2}$ & & & \\
3 & 0.45 & 0.50 & $\mathbf{0 . 8 3}$ & $\mathbf{0 . 7 4}$ & \\
4 & 0.27 & 0.27 & 0.58 & 0.60 & $\mathbf{0 . 7 5}$ \\
5
\end{tabular}

\footnotetext{
33 Coeficientes de correlação variam entre 1 e -1 e indicam a força de uma relação entre duas variáveis, de forma que 1 (ou -1) indica uma correlação positiva (ou negativa) perfeita, enquanto 0 indica variáveis que não se correlacionam de maneira alguma.
} 
A alta correlação entre os itens individuais se confirma em uma altíssima correlação ${ }^{34}$ entre as pontuações agregadas dos participantes nos dois momentos.

Gráfico 3 - Correlação entre as pontuações agregadas na escala nas duas fases do estudo 3

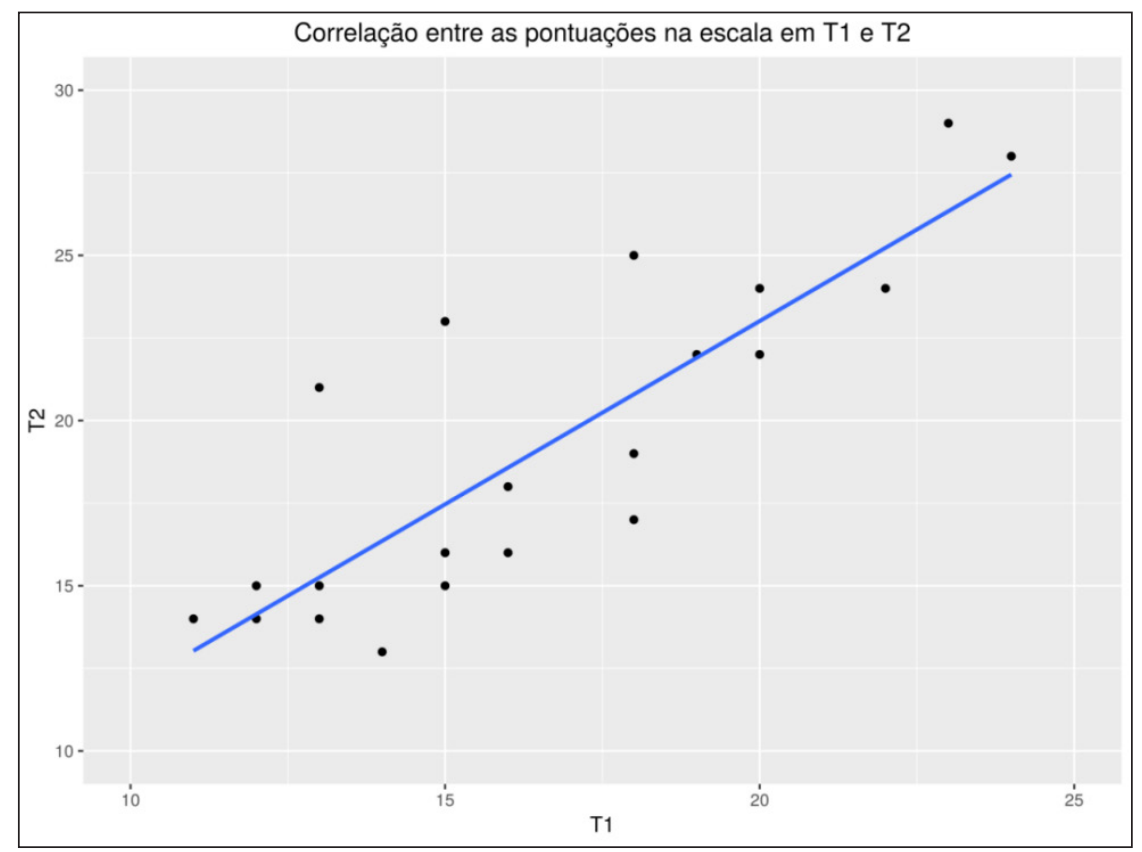

Fonte: os autores.

Finalmente, a pontuação em T1 foi um bom preditor do julgamento realizado em T2, ainda que pior que a pontuação em T2.35

Tabela 5 - Resultados da regressão logística com todos os participantes do estudo 3

\begin{tabular}{lc}
\hline & Modelo 3 - Regrassão logística com todos os participantes \\
\cline { 2 - 2 } & Variável independente \\
\cline { 2 - 2 } Gênero & Resposta $(0=$ contra, 1 = a favor da liberdade de expressão) \\
Pontuação na escala (T1) & 0.486 \\
Constant & $(0.594)$ \\
& $1.560^{* *}$ \\
Observations & $(0.334)$ \\
Log Likelihood & $0.001^{* *}$ \\
Akaike Inf. Crit. & $(0.002)$ \\
\hline
\end{tabular}

Fonte: os autores.

Nota: ${ }^{*} \mathrm{p}<0.1 ;{ }^{* *} \mathrm{p}<0.05 ;{ }^{* * *} \mathrm{p}<0.01$

$\overline{34} r=0,85, p<0,001$.

35 Correlação ponto-bisserial entre pontuação em T1 e julgamento $=0,53, \mathrm{p}<0,05$; correlação ponto-bisserial entre pontuação em T2 e julgamento $=0,82, \mathrm{p}<0,001$. 


\section{Discussão}

As posições a respeito da liberdade de expressão parecem se manter razoavelmente constantes ao longo do tempo, pelo menos quando consideramos intervalos pequenos. Isso implica, inclusive, a possibilidade de prevermos julgamentos temporalmente separados a partir de uma pontuação inicial.

Uma objeção possível aos nossos resultados é que eles não capturam uma distância temporal suficientemente dilatada para que possamos inferir a estabilidade das posições a respeito da liberdade de expressão. Para afastar essa crítica, é importante clarificar nossas conclusões: ao afirmar que as atitudes frente à liberdade de expressão permanecem razoavelmente constantes, não estamos defendendo nenhum determinismo a respeito dessas atitudes; nosso objetivo é simplesmente mostrar que os estados psicológicos mais imediatos não parecem exercer influência sobre elas. Por mais que as posições filosóficas de uma pessoa não costumem se alterar de maneira substantiva em um intervalo de duas semanas, o mesmo não pode ser dito a respeito de seus estados psicológicos. É difícil imaginar, por exemplo, que os participantes tenham memorizado as respostas que deram para os itens da escala no primeiro dia, ou que tivessem exatamente o mesmo conteúdo representado mentalmente nas duas ocasiões. Assim, qualquer que seja a causa dessas atitudes e qual seja a persistência que elas têm ao longo de uma vida, parece claro que estamos falando de características, e não meramente de estados.

\section{Conclusão provisória}

Um defensor do particularismo poderia objetar que nossos testes, até agora, foram muito pouco controlados e que seria necessário perquirir sobre o status moral de cada caso de maneira mais sistemática. Ele poderia enfraquecer sua posição, por exemplo, e conceder que, em alguns casos particularmente difíceis, o único fator de diferenciação é, de fato, a posição normativa preferida do julgador. Mas, continuaria o particularista, isso não é necessariamente assim. Existe um conjunto de casos onde os resultados de fato são determinados pelas peculiaridades do caso concreto e esse conjunto é suficientemente grande para justificar sua posição.

Nós poderíamos simplesmente retrucar que a influência exercida pelas preferências particulares de cada um em pelo menos 4 casos diferentes é indicativa de que o particularismo, em geral, se transforma em uma espécie de decisionismo. Essa resposta apontaria que, ainda que em alguns casos especialmente claros o particularismo indique resultados que independem das posições morais prévias, isso não é suficiente para defender esse modelo de tomada de decisão das objeções levantadas pelos Estudos 1 e 2. Afinal, ainda que esses casos sejam considerados indecidíveis em virtude das suas características particulares (o balanço de razões é tal, segundo essa concepção, 
que não existe uma resposta correta para o caso), não existiria certo valor em tratá-los de maneira isonômica?

Embora seja possível defender nossa posição nesses termos, a objeção particularista merece ser enfrentada de maneira empírica e sistemática.

\section{Estudo 4 \\ Procedimento}

Para testar de maneira mais rigorosa os efeitos exercidos pelas peculiaridades de cada caso, desenhamos um estudo que levava em consideração a dificuldade relativa de uma gama maior de vinhetas. Para obter uma variável que mapeasse a dificuldade ou tendência de julgamento dos casos, realizamos um estudo preparatório, no qual 5 membros da PLEB $^{36}$ foram instruídos a classificar 10 acórdãos do Tribunal de Justiça do Rio de Janeiro que envolviam conflitos entre a liberdade de expressão e a honra de políticos. Essa avaliação se deu em uma escala de 5 pontos onde 1 representava um caso fácil no qual o resultado correto favorecia a liberdade de expressão e 5 representava um caso fácil no qual o resultado correto favorecia a honra do político. Os pesquisadores mostraram alto grau de concordância com relação à tarefa de classificação, ${ }^{37}$ de maneira que usamos a média dos valores atribuídos por eles a cada decisão como uma métrica global para a tendência de julgamento do acórdão.

A seguir, adaptamos os acórdãos para um conjunto de vinhetas sucintas que contivesse o máximo possível das características relevantes constantes do processo que lhe deu origem. ${ }^{38} \mathrm{Um}$ caso foi excluído por se fundar em situação jurídica discrepante dos demais (direito ao esquecimento). As 9 vinhetas restantes foram incluídas na versão final do questionário. Cada participante recebia aleatoriamente 4 dos 9 casos e era instruído a julgá-los (procedentes ou improcedentes) em sequência (ou seja, cada participante via um caso de cada vez e não podia alterar sua resposta depois de ter passado para o caso subsequente). A ordem de apresentação dos 4 casos era determinada randomicamente.

Pela primeira vez, controlamos também a ordem na qual os participantes respondiam aos itens da escala. Na primeira variação, os participantes deveriam responder primeiro aos 4 casos e

\footnotetext{
36 Os membros foram: o primeiro autor (Guilherme Almeida), Alice Kopke Unsonst, Arianne Câmara Nery, Fernanda de Menezes Araújo e Victor Campos Clement Leahy. Agradecemos a cada um dos codificadores por tornarem esta pesquisa possível.

37 O coeficiente de correlação intraclasse (GAMER; LEMON; SINGH, 2012) entre as avaliações dos membros foi 0,7, o que indica um grau expressivo de concordância (CICCHETI, 1994). Duas das codificadoras realizaram a tarefa em conjunto, tendo sido, portanto, consideradas apenas um codificador para efeitos do teste de correlação intraclasse realizado.

38 A adaptação foi realizada pelo primeiro autor, consultando os processos originais e notas tomadas pelos demais codificadores. Após, todos os pesquisadores que participaram da pesquisa tiveram a oportunidade de se manifestar a respeito da adaptação e expressaram sua concordância.
} 
depois aos itens da escala (ordem $=1$ ), enquanto na segunda, os respondentes respondiam primeiro aos itens da escala para posteriormente julgarem cada um dos 4 casos sorteados (ordem $=2$ ).

Os dados dessa etapa preliminar, bem como os métodos utilizados para a análise dos resultados do estudo 4 foram pré-registrados na OSF $^{39}$ antes do início da coleta de dados.

\section{Resultados}

Participaram do estudo 188 pessoas (média de idade $=31,54$, mulheres $=100$ ). Destes, 128 (média de idade $=31,27$; mulheres $=72$ ) se autodeclararam estudantes ou profissionais do direito e foram considerados juristas. A distribuição dos julgamentos com relação aos casos variou de maneira expressiva. O caso mais favorável à liberdade de expressão foi o caso 7 , no qual 95,16\% dos juristas tomaram decisões neste sentido. Em contraste, apenas 3,77\% dos juristas julgaram de maneira favorável à liberdade de expressão no caso 3. Os dados se encontram sumarizados na tabela abaixo:

Tabela 6 - Estatísticas descritivas do estudo 4

\begin{tabular}{|c|c|c|c|}
\hline Vinheta & Tendência & Juristas (\% pró LE) & Leigos (\% pró LE) \\
\hline $\begin{array}{l}\text { Caso } 7 \text { - Jornal noticiou que um vereador } \\
\text { chamou uma vereadora de "office girl" do } \\
\text { prefeito. Indignado, o vereador acionou o jornal. }\end{array}$ & 1 & $95.16 \%$ & $78.95 \%$ \\
\hline $\begin{array}{l}\text { Caso } 6 \text { - Cidadão disse em redes sociais que o } \\
\text { prefeito contratava funcionários fantasmas } \\
\text { (post com } 1 \text { único compartilhamento). }\end{array}$ & 1.5 & $89.83 \%$ & $72 \%$ \\
\hline $\begin{array}{l}\text { Caso } 9 \text { - Cidadão cria grupo nas redes sociais nas } \\
\text { quais publica críticas a um vereador, afirmando } \\
\text { que um de seus assessores comprou o diploma. }\end{array}$ & 1 & $72.22 \%$ & $45.16 \%$ \\
\hline $\begin{array}{l}\text { Caso } 8 \text { - Ex-presidente processa revista que } \\
\text { publicou matéria afirmando que ele usava } \\
\text { drogas e tentara agredir sua esposa. }\end{array}$ & 1 & $72.13 \%$ & $74.07 \%$ \\
\hline $\begin{array}{l}\text { Caso } 1 \text { - Jornalista chamou candidato a prefeito } \\
\text { de mentiroso, mal caráter, ladrão. }\end{array}$ & 2 & $62.5 \%$ & $28 \%$ \\
\hline $\begin{array}{l}\text { Caso } 5 \text { - Cidadão chamou político local de } \\
\text { estelionatário e caloteiro nas redes sociais. }\end{array}$ & 2.5 & $56.36 \%$ & $50 \%$ \\
\hline $\begin{array}{l}\text { Caso } 4 \text { - Jornalista fez paródia do jingle de } \\
\text { prefeito, chamando ele de "rei da corrupção". }\end{array}$ & 1.75 & $54.84 \%$ & $52.38 \%$ \\
\hline $\begin{array}{l}\text { Caso } 2 \text { - Deputado chamou candidato a } \\
\text { governador de Hitler e disse que ele assaltou os } \\
\text { cofres públicos. }\end{array}$ & 4 & $50 \%$ & $36.11 \%$ \\
\hline $\begin{array}{l}\text { Caso } 3 \text { - Jornal publicou que candidato a } \\
\text { prefeito era réu no TCE, mas, na verdade, não } \\
\text { existia processo. }\end{array}$ & 4.25 & $3.77 \%$ & $7.69 \%$ \\
\hline
\end{tabular}

Fonte: os autores.

39 A OSF (Open Science Foundation) é uma ONG internacional que tem como objetivo aumentar a qualidade das conclusões científicas em ciências sociais aplicadas. $O$ pré-registro de experimentos antes do início da coleta dos dados tem sido uma estratégia incentivada pela academia internacional, propiciando ganhos significativos em robustez. Vide Munafò et al. (2017, p. 3-4) e Open Science Collaboration (2015). 
A variável obtida na fase preliminar do estudo, que tinha como objetivo mapear a tendência de julgamento dos casos, correlacionou-se de maneira bastante alta com as médias de provimento, mesmo quando consideramos apenas os respondentes que se declararam juristas. ${ }^{40}$ Por esse motivo, utilizamos essa medida como variável independente dos modelos que usamos para testar nossas hipóteses.

Tabela 7 - Resultados da regressão logística com todos os participantes do estudo 4

\begin{tabular}{lc}
\hline & Modelo 4 - Regressão logística com todos os participantes \\
\hline & Vespostável independente \\
\cline { 2 - 2 } Gênero 0 contra, $1=$ a favor da liberdade de expressão $)$ \\
Idade & 1.257 \\
& $(0.324)$ \\
Ordem & 0.999 \\
& $(0.011)$ \\
Pontuação na escala & $1.915^{* *}$ \\
& $(0.498)$ \\
Tendência do caso & $2.061^{* * *}$ \\
Constant & $(0.286)$ \\
& $3.998^{* * *}$ \\
\hline Observations & $(1.401)$ \\
Log Likelihood & $0.063^{* * *}$ \\
Akaike Inf. Crit. & $(0.105)$ \\
\hline Bayesian Inf. Crit. & 752 \\
Fonte: OS autor. & -390.592 \\
\end{tabular}

Fonte: os autores.

Nota: ${ }^{*} p<0.1 ;{ }^{* *} p<0.05 ;{ }^{* *} p<0.01$.

modelo acima confirma as hipóteses levantadas, haja vista a significância estatística do termo indicativo da pontuação que o respondente obteve na escala de liberdade de expressão, mesmo com todas as variáveis de controle alimentando o modelo. Observaram-se, ainda, efeitos significativos de ordem (participantes que foram expostos à escala primeiro tenderam a responder de maneira mais favorável à liberdade de expressão) e tendência (quanto maior a pontuação na tendência - indicando um favorecimento ao direito à liberdade de expressão -, mais vezes o caso foi julgado a favor da liberdade de expressão).

Quando levamos em consideração o termo da interação entre pontuação na escala e dificuldade do caso, os efeitos exercidos pela pontuação na escala de liberdade de expressão continuam estatisticamente significativos.

$\overline{40 \quad r=0,83, \mathrm{p}<0,005}$. 
Tabela 8 - Resultados da regressão logística envolvendo todos os participantes no estudo 4

\begin{tabular}{lc}
\hline & Modelo 5 - Regressão logística com todos os participantes \\
\cline { 2 - 2 } Gênero & Variável independente \\
\cline { 2 - 2 } Idade & Resposta $(0=$ contra, 1 a favor da liberdade de expressão) \\
& 1.272 \\
Ordem & $(0.333)$ \\
& 0.998 \\
Pontuação na escala & $(0.011)$ \\
Tendência do caso & $1.954^{* *}$ \\
Interação entre pontuação e & $(0.516)$ \\
tendência & $2.083^{* * *}$ \\
Constant & $(0.296)$ \\
& $4.085^{* * *}$ \\
\hline Observations & $(1.418)$ \\
Log Likelihood & $1.374^{* * *}$ \\
Akaike Inf. Crit. & $(0.162)$ \\
\hline Bayesian Inf. Crit. & 1.102 \\
\hline
\end{tabular}

Fonte: os autores.

Nota: ${ }^{*} \mathrm{p}<0.1 ;{ }^{* *} \mathrm{p}<0.05 ;{ }^{* * *} \mathrm{p}<0.01$

Os resultados se mantiveram quando consideramos apenas os respondentes juristas.

Tabela 9 - Regressão aplicada apenas a juristas (estudo 4)

\section{Modelo 6 - Regressão logística com juristas}

\begin{tabular}{lc}
\hline & Variável independente \\
\cline { 2 - 2 } Gênero & Resposta $(0=$ contra, 1 a favor da liberdade de expressão $)$ \\
Idade & 1.734 \\
& $(0.647)$ \\
Ordem & 1.013 \\
& $(0.017)$ \\
Pontuação na escala & $2.091^{* *}$ \\
& $(0.778)$ \\
Tendência do caso & $2.510^{* * *}$ \\
Interação entre pontuação e & $(0.521)$ \\
tendência & $5.699 * * *$ \\
Constant & $(2.535)$ \\
& $1.641^{* * *}$ \\
\hline Observations & $(0.266)$ \\
Log Likelihood & 0.890 \\
Akaike Inf. Crit. & $(0.641)$ \\
\hline Bayesian Inf. Crit. & 512 \\
Fonte: os autores. & -238.812 \\
\hline
\end{tabular}

Fonte: os autores.

Nota: ${ }^{*} p<0.1 ;{ }^{* *} p<0.05 ;{ }^{* *} p<0.01$. 
O gráfico abaixo representa esses efeitos:

Gráfico 4 - Julgamento previsto como função da pontuação na escala no estudo 4

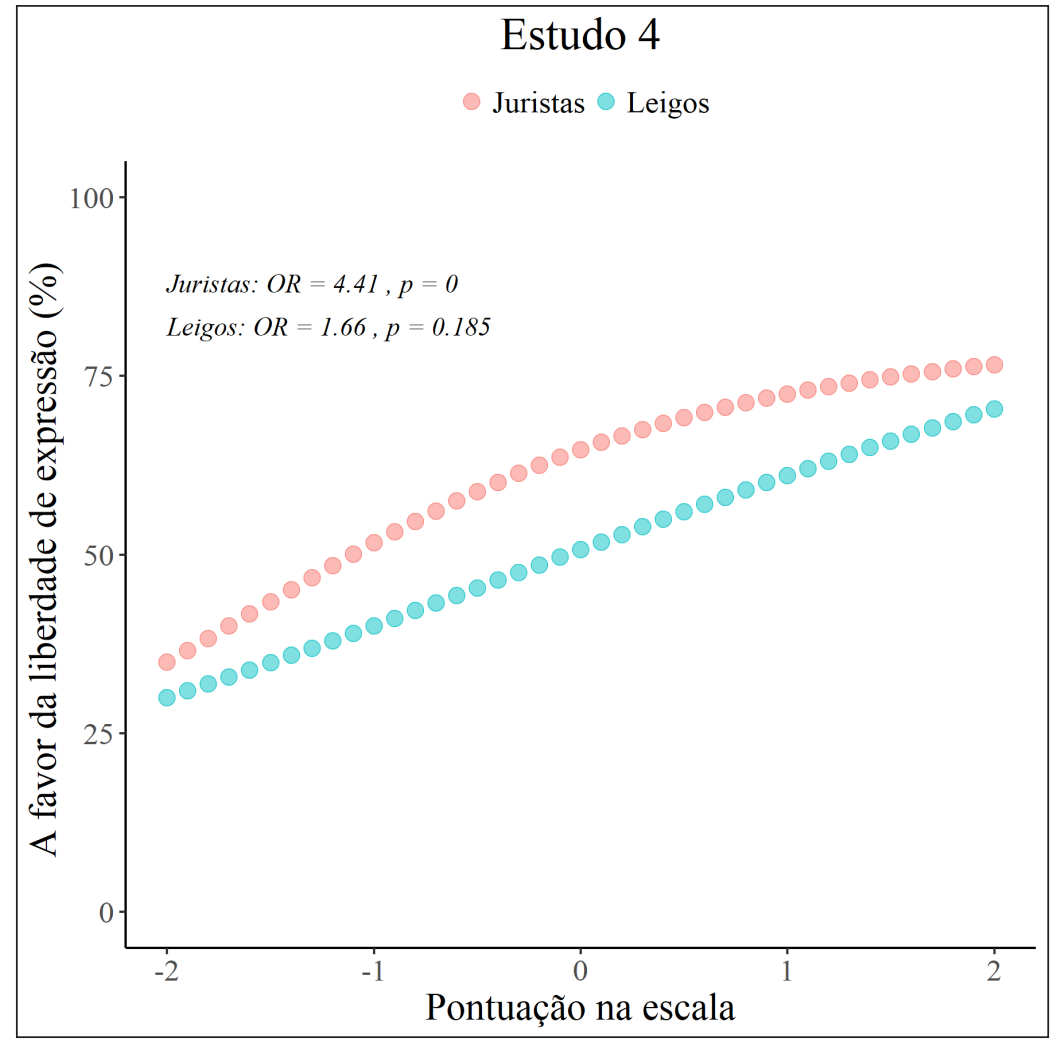

Fonte: os autores.

O resultado positivo do termo de interação indica que, nos casos com tendência favorável à liberdade de expressão - presumivelmente casos que envolvem violações menos graves da honra e da imagem de políticos -, há uma influência bastante elevada das posições prévias. Nesses casos, as pessoas que são a favor da liberdade de expressão tomam decisões pró-liberdade de expressão na grande maioria dos casos, enquanto aquelas que são mais favoráveis ao direito à honra tomam decisões no sentido oposto quase sempre. Em contraste, quando falamos dos casos com uma tendência mais favorável ao direito à honra e à imagem - envolvendo violações consideradas mais graves pelos respondentes - a influência exercida pelas posições prévias é menor. Ou seja, alguns casos são suficientemente graves para fazer com que mesmo os amantes da liberdade de expressão tomem decisões que são contrárias a esse direito. Esses resultados estão graficamente representados abaixo: 
Gráfico 5 - Interação entre pontuação na escala e tendência do caso

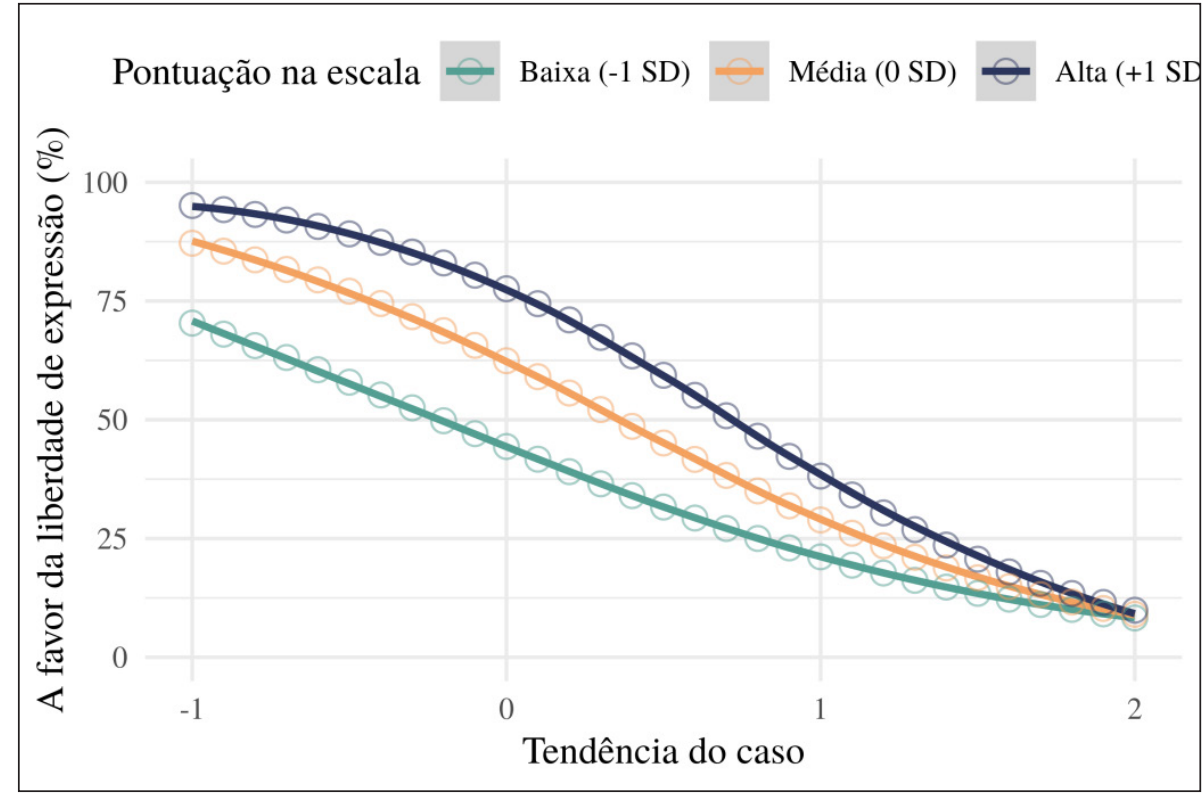

Fonte: os autores.

A distância entre as linhas no gráfico acima representa o tamanho do efeito exercido pela posição quanto à liberdade de expressão. Nos casos de violações mais graves à honra e à imagem (no canto direito do gráfico), essa distância é bastante reduzida - nesses casos, quase todos tomam decisões contrárias à liberdade de expressão -, mas as posições prévias seguem fazendo diferença mesmo em casos que tendem levemente para um lado ou para o outro.

\section{Discussão}

As atitudes das pessoas com relação à liberdade de expressão preveem seus julgamentos mesmo quando controlamos variáveis que possuem uma relação estatisticamente significativa com o resultado do caso, como sua dificuldade e a ordem de apresentação da escala, que parece funcionar como um priming em favor da liberdade de expressão. Quando levamos em consideração a interação entre a dificuldade do caso e as posições prévias dos respondentes, notamos que a pontuação na escala exerce um efeito maior quando os casos tendem a ser julgados a favor da liberdade de expressão. Uma possível explicação para esse fenômeno envolve a gravidade das violações envolvidas em cada tipo de caso. Quando as violações à honra e à imagem são mais graves, mesmo pessoas mais próliberdade de expressão proferem julgamentos favoráveis aos direitos da personalidade, ainda que a posição prévia continue exercendo alguma influência. Nesse sentido, parece que as diretivas vagas que controlam os conflitos entre liberdade de expressão e os direitos à honra e à imagem no Brasil oferecem pelo menos alguma pressão sobre os julgamentos. Pelo menos algumas das características moralmente relevantes do caso importam para o seu julgamento. $\bigcirc$ particularista, porém, segue 
sem motivos para comemorar: mesmo nesses casos, ainda subsiste uma influência significativa das posições prévias de cada julgador.

Algumas hipóteses interessantes surgem a partir desses resultados. Qual é, por exemplo, a relação entre a dificuldade de um caso e a influência exercida pelas posições prévias? Será que o efeito que observamos é maior em casos mais difíceis (de penumbra, que não tendem nem para um lado, nem para o outro)? As posições prévias fazem alguma diferença em casos fáceis? Por outro lado, será que o efeito exercido pelas particularidades do caso concreto é em parte uma função da posição prévia dos julgadores? Em outras palavras: será que radicais não atentam para as características moralmente relevantes de cada caso, mas o conjunto maior de moderados é sensível a essas variações? Apenas pesquisas mais aprofundadas poderão responder a essas perguntas.

\section{Conclusão}

No presente artigo, exploramos experimentalmente uma série de hipóteses a respeito dos julgamentos jurídicos sobre conflitos entre a liberdade de expressão e o direito à honra e à imagem. Escolas como neoconstitucionalismo e direito civil-constitucional criticam a adoção de regras para a resolução de conflitos entre esses dois direitos (e entre direitos fundamentais em geral), e apostam na ponderação casuística como o método mais adequado para solucionar tais conflitos. Experimentos, contudo, têm revelado que os julgadores chegam a resultados distintos, ainda que concordem com o "método" - o que também pode ser identificado em decisões judiciais sobre o tema (LEITE, 2018, p. 9-10).

Os estudos apresentados neste trabalho indicam que, na ausência de regras, as decisões são fortemente influenciadas pelas posições normativas do julgador a respeito dos direitos em conflito, o que abre espaço para um decisionismo difícil de se defender do ponto de vista normativo. Se nossa análise estiver correta, a doutrina civilista e neoconstitucionalista rejeita soluções normativas prévias, a partir de regras, mas aposta num método cujo resultado irá variar de acordo com os juízos prévios de cada julgador. Por que as preferências normativas do juiz devem se sobrepor às preferências normativas do legislador? Não seria mais democrático e isonômico aceitar a criação de regras por via legislativa em conflitos entre liberdade de expressão e direito à honra e à imagem? Se o que vale para a liberdade de expressão também valer para outros direitos fundamentais, parece ser uma boa ideia rever os pressupostos do neoconstitucionalismo.

A alternativa à visão atualmente predominante é aceitar a criação e subsequente aplicação de regras claras aos conflitos entre direitos fundamentais, reduzindo o poder discricionário dos juízes. Acreditamos que a opção formalista oferece uma resposta adequada para os desafios que encontramos, mas os estudos realizados até aqui não são suficientes para embasar essa posição. Afinal, um realista particularmente radical poderia concordar com nossa crítica do particularismo, mas afirmar que a introdução de regras claras não mudaria nada. Segundo esse crítico, em casos moralmente salientes, como os conflitos entre direitos fundamentais, pouco importa o conteúdo 
do direito positivo, porque os juízes irão aproveitar sua posição para promover os valores que lhe são caros. A partir dessa perspectiva, os resultados sequer são surpreendentes, o que mostra que ela precisa ser enfrentada de maneira empírica.

Estudos subsequentes devem usar a escala de liberdade de expressão/direito à honra e à imagem desenvolvida no presente artigo para refinar nosso entendimento a respeito da influência que diferentes tipos de prescrições jurídicas (regras, princípios, critérios, métodos de ponderação e afins) exercem sobre nossos julgamentos, testando as previsões do realista cético e clarificando as interações entre a dificuldade dos casos e nossas próprias preferências morais.

\section{Referências}

ALEXANDER, Larry; SHERWIN, Emily. Demystifying Legal Reasoning. Cambridge: Cambridge University Press, 2008.

ALMEIDA, Guilherme da Franca Couto Fernandes de. Técnica legislativa e linguagem. 2017. Dissertação (Mestrado em Direito) - Pontifícia Universidade Católica do Rio de Janeiro, Rio de Janeiro, 2017.

BARROSO, Luis Roberto. Colisão entre liberdade de expressão e direitos da personalidade. Critérios de ponderação. Interpretação constitucionalmente adequada do código civil e da lei de imprensa. Revista de Direito Administrativo, v. 235, p. 1-36, 2004.

BRASIL. Constituição: República Federativa do Brasil de 1988. Brasília, DF: Senado Federal, 1988.

BRASIL. Lei n. 11.343, de 23 de agosto de 2006. Institui o Sistema Nacional de Políticas Públicas sobre Drogas - Sisnad; prescreve medidas para prevenção do uso indevido, atenção e reinserção social de usuários e dependentes de drogas; estabelece normas para repressão à produção não autorizada e ao tráfico ilícito de drogas; define crimes e dá outras providências. Diário Oficial da União, Brasília, DF, 24 ago. 2006.

BRASIL. Superior Tribunal de Justiça. Recurso Especial n. 801.249/SC. Diário da Justiça, Brasília, DF, 17 set. 2007.

CENTRO DE ESTUDOS JUDICIÁRIOS. Jurisprudência do Tribunal Europeu dos Direitos do Homem: Casos Nacionais. Lisboa, Portugal: Centro de Estudos Judiciários, 2013. (Coleção Ações de Formação). Disponível em: http://www.cej.mj.pt/cej/recursos/ebooks/Jurisprudencia/Jurisprudencia_ Tribunal_Europeu_Direitos_Homem.pdf. Acesso em: 30 mar. 2019.

CICCHETI, Domenic V. Guidelines, criteria, and rules of thumb for evaluating normed and standardized assessment instruments in psychology. Psychological assessment, [S. l.], v. 6, n. 4, p. $284-$ 290, 1994.

GAMER, Matthias; LEMON, Jim; SINGH, Ian Fellows Puspendra. irr: Various coefficients of interrater reliability and agrément. Pacote para R. 2012. Disponível em: https://CRAN.R-project.org/ package=irr. Acesso em: 2 ago. 2017. 
HARTMANN, Ivar Alberto Martins. Manifestação, honra e ódio na internet. A proteção da liberdade de expressão por meio da capacidade comunicativa e da autorregulação. Tese (Doutorado) - Universidade do Estado do Rio de Janeiro, Rio de Janeiro, 2018.

HENRIQUES, Ana; BARATA, Clara; PEDRO, Tiago Luz. Lei da liberdade de expressão "podia ser melhorada" em Portugal. Público P, 17 dez. 2016. Disponível em: https://www.publico. pt/2016/12/17/sociedade/entrevista/lei-da-liberdade-de-expressao-podia-ser-melhorada-1755157. Acesso em: 30 mar. 2019.

INTERNATIONAL PRESS INSTITUTE. Briefing: Criminal Defamation in Portugal. Vienna, Austria: International Press Institute, 2015. Disponível em: http://img.rtp.pt/icm/noticias/docs/46/4637b0e50557c321e87b04364452a430_5796b7db09223d11c972a067a8c660aa.pdf. Acesso em: 30 mar. 2019.

KAHAN, Dan M. et al. 'Ideology" or 'Situation Sense'? An experimental investigation of motivated reasoning and professional judgement. University of Pennsylvania Law Review, Philadelphia, v. 164, i. 2, p. 349-439, 2016.

LEAL, Fernando. Seis objeções ao direito civil constitucional. Revista Brasileira de Direitos Fundamentais e Justiça, Belo Horizonte, ano 9, n. 33, p. 123-165, 2015.

LEITE, Fábio Carvalho; FRAJHOF, Isabella Zalcberg. Direito ao Esquecimento: Reflexões sobre o Nome e a Coisa. In: LEITE, Fábio Carvalho; ABREU, Célia Barbosa; PEIXINHO, Manoel Messias (org.). Temas de Direitos Humanos. Rio de Janeiro: Lumen Juris, 2018. v. 1.

LEITE, Fábio Carvalho; HANNIKAINEN, Ivar Allan Rodriguez; NHUCH, Flavia Kamenetz. Adivinhe quem vem para jantar. A liberdade de expressão do ofensor e o subjetivismo do julgador na análise dos crimes de injúria. Revista da Faculdade de Direito - UFPR, Curitiba, v. 61, n. 3, p. 259276, 2016.

LEITE, Fábio Carvalho; HANNIKAINEN, Ivar Allan Rodriguez. O uso de experimentos na pesquisa jurídica: experiências com a liberdade de expressão. In: CUNHA, Antônio Renato Cardoso da; ABREU, Célia Barbosa; PEIXINHO, Manoel Messias (org.). Diretrizes de metodologia de pesquisa jurídica. Rio de Janeiro: Lumen Juris, 2018. v. 1.

LEITE, Fábio Carvalho. Por uma posição preferencial do direito de resposta nos conflitos entre liberdade de Imprensa e direito à honra. Civilistica.com, [S. l.], ano 7, n. 1, p. 1-25, 2018.

LIAW, Andy; WIENER, Matthew. Classification and regression by randomForest. R News, [S. l.], v. 2, n. 3, p. 18-22, 2002. Disponível em: https://cran.r-project.org/package=randomForest. Acesso em: 18 maio 2017.

MORAES, Maria Celina Bodin de. O jovem direito civil-constitucional. Civilistica.com, [S. l.], ano 1, n. 1, 2012. Disponível em: http://civilistica.com/o-jovem-direito-civil-constitucional/. Acesso em: 10 ago. 2018.

MUNAFÒ, Marcus R. et al. A manifesto for reproducible science. Nature Human Behaviour, [S. 1.], v. 1, 2017. Disponível em: https://www.nature.com/articles/s41562-016-0021.pdf. Acesso em: 26 fev. 2018. 
OPEN SCIENCE COLLABORATION. Estimating the reproducibility of psychological science. Science, [S. l.], v. 349, n. 6251, 2015. Disponível em: https://osf.io/shr96/register/5730e99a9ad5a102c5745a8a. Acesso em: 30 mar. 2019.

PORTUGAL. Tribunal da Relação de Lisboa. Acórdão

2175/11.4TDLSB.L1-9. Lisboa, Portugal, 26 jan. 2017. Disponível em: http://www.dgsi.pt/jtrl. nsf/33182fc732316039802565fa00497eec/2539879f68366f6e802580b8004a8a5b? OpenDocument. Acesso em: 30 mar. 2019.

REVELLE, William. psych: Procedures for personality and psychological research. Evanston: Northwestern University, 2017. Disponível em: https://CRAN.R-project.org/package=psych. Acesso em: 18 maio 2017.

SCHAUER, Frederick. Prescriptions in three dimensions. Iowa Law Review, [S. l.], v. 82, p. 911-922, 1997.

SILVA, Virgílio Afonso da. Interpretação constitucional e sincretismo metodológico. In: SILVA, Virgílio Afonso da (org.). Interpretação constitucional. São Paulo: Malheiros, 2005. 